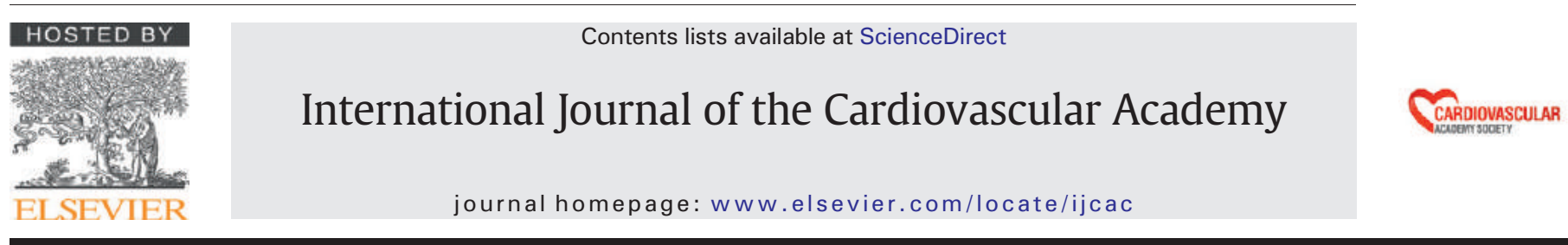

Case report

\title{
Cleft in aortic valve
}

\author{
Kinnaresh Baria ${ }^{a}$, Amit Mishra ${ }^{\mathrm{b}, *}$, Ritesh Shah ${ }^{\mathrm{c}}$

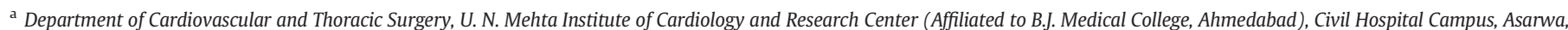 \\ Ahmedabad 380016, India

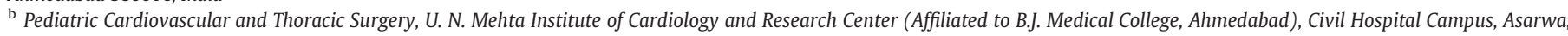 \\ Ahmedabad 380016, India

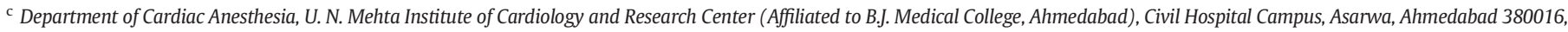 \\ India
}

\section{A R T I C L E I N F O}

\section{Article history:}

Received 4 January 2016

Received in revised form 10 February 2016

Accepted 10 February 2016

Available online 5 March 2016

Keywords:

Congenital

Aortic valve cleft

Aortic Insufficiency

\begin{abstract}
A B S T R A C T
Congenital aortic valve cleft is a rare entity with scanty literature available. Cleft in aortic valve can be congenital, degenerative or age related. Sudden rupture of cusps can lead to severe aortic insufficiency requiring surgical intervention. With this we acknowledge a case where patient had aortic insufficiency due to cleft in right coronary cusp with perimembranous ventricular septal defect.

(C) 2016 The Society of Cardiovascular Academy. Production and hosting by Elsevier B.V. All rights reserved. This is an open access article under the CC BY-NC-ND license (http://creativecommons.org/licenses/by-nc-nd/4.0/).
\end{abstract}

\section{Case detail}

A 9 year old boy, who has been diagnosed recently as suffering from congenital ventricular septal defect and moderate aortic valvular insufficiency, has been admitted with complains of dyspnea NYHA class II and failure to thrive with no history suggestive of rheumatic heart disease or infective endocarditis. Two dimensional echocardiography was suggestive of moderate size perimembranous ventricular septal defect with left to right shunt, moderate aortic insufficiency. At surgery, the findings were confirmed; there was tricuspid aortic valve with cleft in right coronary cusp with no cusp prolapse, without any additional commissures (Fig. 1). The ventricular septal defect was closed with GORETEX® patch, continuous PROLENE® suturing while cleft in right coronary cusp was repaired with interrupted direct PROLENE® sutures (Fig. 2). Post-operative transesophageal echocardiography was suggestive of no flow across interventricular septum with trivial aortic insufficiency.

\footnotetext{
* Corresponding author at: Pediatric Cardiac Surgery, Department of Cardiovascular and Thoracic Surgery, U. N. Mehta Institute of Cardiology and Research Center, (Affiliated to B. J. Medical College), New Civil Hospital Campus, Asarwa, Ahmedabad 380016, Gujarat, India. Tel.: + 9109979203994.

E-mail address: drmishraamit@yahoo.com (A. Mishra).

Peer review under responsibility of The Society of Cardiovascular Academy.
}

\section{Funding}

This work was supported by U.N. Mehta Institute of Cardiology and Research Center itself and received no specific grant from any funding agency, commercial or not-for-profit sectors.

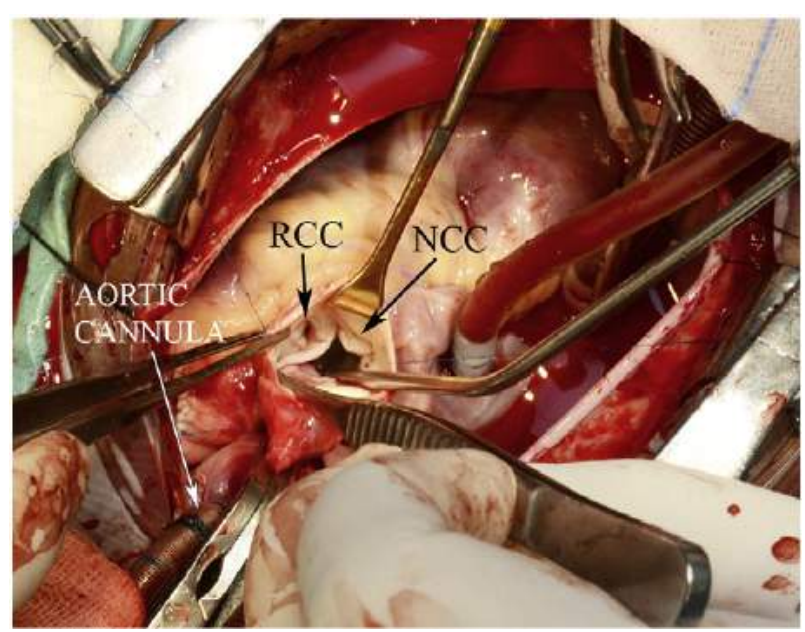

Fig. 1. Perioperative photograph demonstrating cleft in aortic valve right coronary cusp. 


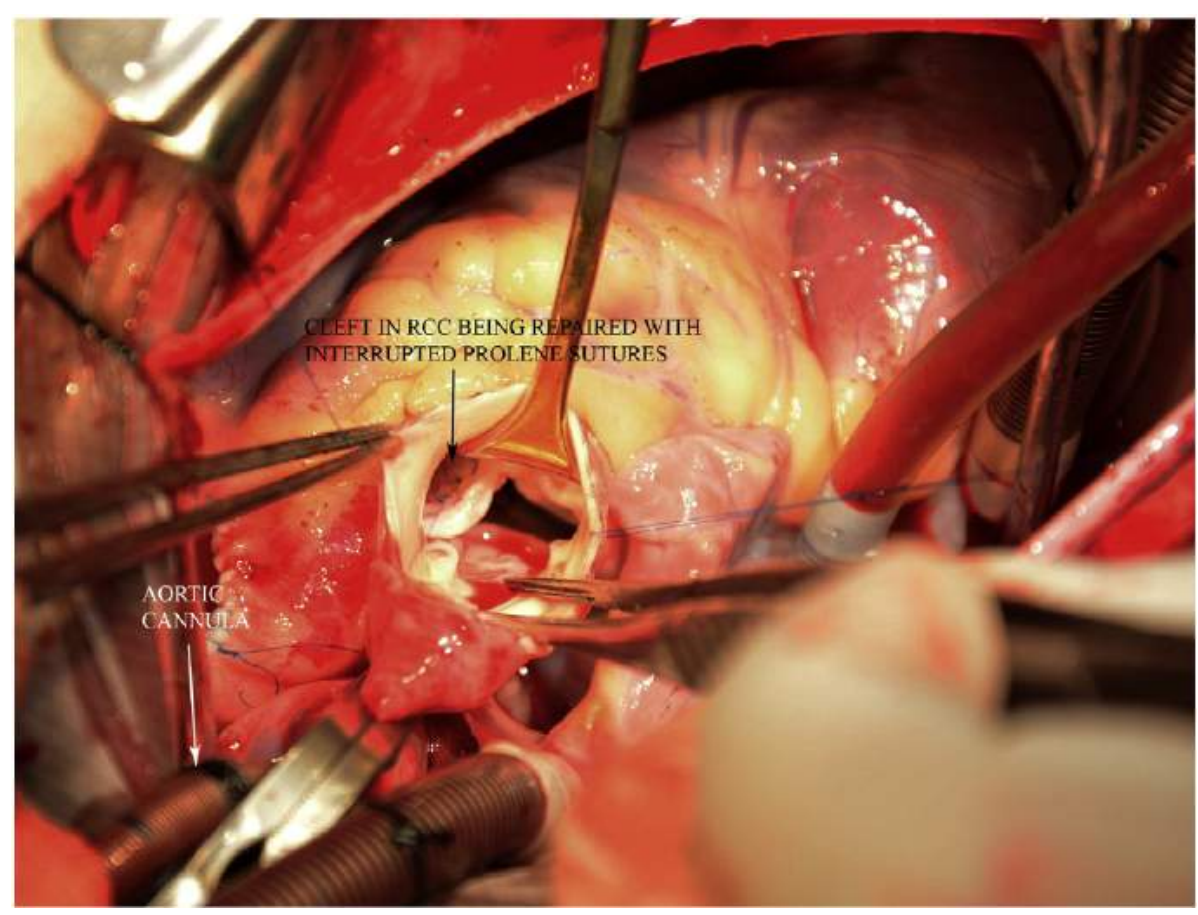

Fig. 2. Perioperative photograph demonstrating cleft being repaired with direct PROLENE® sutures.

\section{Conflict of interest}

None declared. 